\title{
Accumulation of Hippocampal Place Fields at the Goal Location in an Annular Watermaze Task
}

\author{
Stig A. Hollup, ${ }^{1}$ Sturla Molden, ${ }^{1}$ James G. Donnett, ${ }^{2}$ May-Britt Moser, ${ }^{1}$ and Edvard I. Moser ${ }^{1}$ \\ ${ }^{1}$ Department of Psychology, Norwegian University of Science and Technology, 7491 Trondheim, Norway, and ${ }^{2}$ Axona \\ Ltd., St. Albans, Herts AL3 6EU, United Kingdom
}

To explore the plastic representation of information in spatially selective hippocampal pyramidal neurons, we made multiple single-unit recordings in rats trained to find a hidden platform at a constant location in a hippocampal-dependent annular watermaze task. Hippocampal pyramidal cells exhibited placerelated firing in the watermaze. Place fields tended to accumulate near the platform, even in probe trials without immediate escape. The percentage of cells with peak activity around the hidden platform was more than twice the percentage firing in equally large areas elsewhere in the arena. The effect was independent of the actual position of the platform in the room

The hippocampus appears to be necessary for several types of memory (Squire, 1992; Morris and Frey, 1997; Eichenbaum et al., 1999), but its mnemonic function is particularly clear in tasks for which subjects are required to remember spatial location (O'Keefe and Nadel, 1978). Rats with hippocampal lesions exhibit impairments in both encoding and retrieval of spatial memory (Olton et al., 1978; Morris et al., 1982, 1990). During recall of food locations in a radial maze task, large parts of the hippocampus are activated (Bontempi et al., 1999). A similar activation takes place when humans recall routes in a spatially complex environment (Maguire et al., 1997, 1998).

Despite these advances in our understanding of hippocampal function, the neuronal correlates of memory in the hippocampus remain elusive. It is well established that pyramidal cells have location-specific firing correlates (place fields) and fire in distinct regions of the experimental arena (O'Keefe and Dostrovsky, 1971; Muller et al., 1987; O’Keefe and Speakman, 1987; Wilson and McNaughton, 1993). Such place cells appear to participate in a distributed and nontopographic map-like representation of the spatial environment (O'Keefe and Nadel, 1978), and it is often assumed that they are involved when an animal learns to find its way from one place to another. However, we have yet no clear idea of how hippocampal cells could contribute to goal-directed navigation and goal recognition during spatial learning.

One outstanding issue is whether the distribution of place fields

\footnotetext{
Received Oct. 16, 2000; revised Dec. 13, 2000; accepted Dec. 18, 2000.

This work was supported by Norwegian Research Council Grants 122512/310 and 133958/420 and Fifth Framework Research and Technological Development Program of the European Commission Grant QLG3-CT-1999-00192. We thank J. O'Keefe for introducing M.-B.M. and E.I.M. to unit recording; P. Andersen, K. M. Gothard, L. de Hoz, K. J. Jeffery, J. O'Keefe, R. G. M. Morris, and O. Paulsen for comments on earlier drafts of this manuscript; and A. K. Ammundgård, K. Barmen, K. Haugen, R. Pedersen, and H. T. Skiri for technical assistance.

Correspondence should be addressed to Edvard Moser, Department of Psychology, Norwegian University of Science and Technology, N-7491 Trondheim, Norway. E-mail: edvard.moser@svt.ntnu.no.

Copyright (C) 2001 Society for Neuroscience $\quad 0270-6474 / 01 / 211635-10 \$ 15.00 / 0$
}

frame. It was dissociable from ongoing motor behavior and was not related to linear or angular speed, swim direction, or variation in hippocampal theta activity. There was no accumulation of firing in any particular region in rats that were trained with a variable platform location. These training-dependent effects suggest that regions of particular behavioral significance may be over-represented in the hippocampal spatial map, even when these regions are completely unmarked.

Key words: hippocampus; place cells; learning; memory; recognition; spatial; plasticity; rat matches the behavioral significance of locations along a remembered trajectory. For example, we do not know whether the goal location is represented differently from off-target areas and whether such differential representation, if it exists, develops in parallel with spatial learning. One way to approach such issues is to record single-unit activity from ensembles of hippocampal neurons while rats solve a spatial memory task such as the watermaze. The watermaze is a homogeneous water-filled pool in which rats are trained to find a concealed escape platform by remembering geometric relationships between distal landmarks (Morris et al., 1982). The watermaze is unique in that there are no salient proximal cues, that the goal location is inconspicuous, and that much of the systems approach to understanding hippocampal function is based on this task. However, studies of place cells in the watermaze would be constrained by the fact that a well-trained animal rarely visits all regions of the arena once it has learned the location of the hidden escape platform. We have circumvented this sampling problem by training rats in an annular version of the task, in which the animals must swim one or several laps through the environment before the platform is made available either at a constant or a variable location inside the corridor. There are still no proximal landmarks and the goal is disguised, but the rat covers the entire arena. We used this new task to examine whether the distribution of hippocampal place fields is influenced by what is learned by the animal.

\section{MATERIALS AND METHODS}

Subjects. Thirteen naive male Long-Evans rats (400-600 gm at implantation and testing) were housed individually in large transparent Plexiglas cages $(54 \times 44 \times 35 \mathrm{~cm})$ with food and water available ad libitum. The rats were kept on a $12 \mathrm{hr}$ light/dark schedule and tested in the dark phase.

Electrode implantation. Tetrodes (O'Keefe and Recce, 1993) were made of twisted $17 \mu \mathrm{m}$ polyimide-coated platinum-iridium (90\%-10\%) wire. Two or four of these were mounted in a cannula connected to a lightweight microdrive (Axona Ltd., Herts, UK) and were then implanted in the dorsal hippocampus. 
The animals were anesthetized with Equithesin $(1 \mathrm{ml} / 250 \mathrm{gm})$. A trephine bit was used to drill a $2 \mathrm{~mm}$ hole in the skull overlying the left dorsal hippocampus, and the dura was removed gently. The microdrive and tetrodes were mounted to the stereotaxic frame and lowered slowly until the electrode tips reached the deep layers of the neocortex $(1.7 \mathrm{~mm}$ below the dura) at $4.0 \mathrm{~mm}$ posterior to bregma and $3.2 \mathrm{~mm}$ lateral to the midline. An outer protecting cannula on the microdrive was then lowered down to the dural surface, and gel foam was placed around the cannula to protect the electrodes. Finally, the foot of the microdrive and seven anchoring screws were encased in dental acrylic. One screw served as an electrical ground. The tip of one tetrode was $0.3-0.5 \mathrm{~mm}$ above that of the others. The animals were given 1-2 weeks of recovery before cell screening started.

Cell screening. Screening for hippocampal units took place in a dedicated room $(2.5 \times 4 \mathrm{~m})$. Over the course of $4-8 \mathrm{~d}$, the electrodes were advanced in steps of $\leq 50 \mu \mathrm{m}$ until multiple complex-spiking cells of $>100-150 \mu \mathrm{V}$ amplitude were identified in the hippocampus. The animal rested on a pedestal or walked in an open field during these screening trials. The pedestal was a $30 \times 30 \mathrm{~cm}$ square of stainless steel with a $5 \mathrm{~cm}$ vertical edge on each side. The pedestal was filled with sawdust. The open field is described below. Screening for cells and testing in the watermaze were always conducted in separate rooms.

Recording procedure. The animal was connected to the recording equipment (Axona Ltd.) via cables of hearing-aid wire, one for each channel. The cables were counterbalanced by a pulley and weight system. Signals from each electrode were passed through AC-coupled, unity gain operational amplifiers close to the head of the rat and were later amplified 15,000-25,000 times and bandpass-filtered between $600 \mathrm{~Hz}$ and $6 \mathrm{kHz}$. Each channel on the deep tetrodes was recorded differentially with respect to an electrode on the shallow tetrode. Unit spikes were identified when the signal amplitude crossed a preset threshold manually adjusted to approximately three times the noise level of the channel. Waveforms of identified spikes were sampled at $48 \mathrm{kHz}$ ( 50 points per channel, 10 points before trigger, 40 points after trigger), time-stamped, and stored for off-line analysis. An EEG was recorded single-endedly from one of the shallow electrodes, low-pass filtered at $117 \mathrm{~Hz}$, sampled at $234 \mathrm{~Hz}$, and stored with the unit data. The position of the rat in the apparatus was obtained by a video-tracking system (Axona Ltd.) that extracted the $x--y$ coordinates of a small light-emitting diode on the headstage (in the open field) or of the black head of the rat on the white pool surface (in the watermaze). Positions were sampled at $47 \mathrm{~Hz}$ at a resolution of 4 $\mathrm{mm} /$ pixel. The position data were stored with the unit data.

Open field. The rats were trained to chase sweet rice grains that were scattered individually into a black open field $(100 \times 100 \times 50 \mathrm{~cm})$ at $10-15 \mathrm{sec}$ intervals. The box was made of stainless steel and electrically grounded. A white cue card $(30 \times 20 \mathrm{~cm})$ was centered on one of its walls. Data from the open field were generally recorded before and after testing in the water task.

Annular watermaze. The experiments took place in a watermaze consisting of a white circular polyvinylchloride tank $(198 \mathrm{~cm}$ diameter, $50 \mathrm{~cm}$ deep) filled to a depth of $40 \mathrm{~cm}$ with water at $28 \pm 2^{\circ} \mathrm{C}$. The pool was located in a room $(4 \times 7 \mathrm{~m})$ with multiple distant cues on all sides. Swimming in the watermaze was constrained by two circular, transparent Perspex walls of 75 and $95 \mathrm{~cm}$ diameter, respectively, placed around the center of the tank. The water was made opaque with latex liquid. A $10 \mathrm{~cm}$ diameter escape platform was located within the corridor, either northeast (NE), northwest (NW), southwest (SW), or southeast (SE). The platform could be regulated remotely between an available and an unavailable level ( 1.5 and $22 \mathrm{~cm}$ below the surface, respectively). A wall $(2 \times 2 \mathrm{~m})$ separated the pool from the experimenter during the trials.

Training in the annular watermaze. Animals were trained to escape onto a hidden platform. The active platform was either at a constant location on all trials (nine rats) or the location varied according to a pseudorandom schedule (four rats). In the former condition, the platform was NE for 15 cells, NW for 15 cells, SW for 24 cells, and SE for 26 cells. The platform was always in the submerged (unavailable) position at the start of the trial and was not raised until the rat had swum at least one full lap in the corridor. Start positions were varied between north, south, east, and west in a pseudorandom order. Maximum trial length was $120 \mathrm{sec}$, and the animal rested $30 \mathrm{sec}$ on the platform after each trial. All animals were trained before surgery (four trials in the morning and four trials in the evening for $\geq 5 \mathrm{~d}$ ). After surgery, training continued until the rat was familiar with the recording equipment.

Only the probe trials were analyzed systematically. The corridor was divided into six $60^{\circ}$ segments, with the submerged platform in the center of one of these segments. We measured dwell time as well as swim velocity in each segment.

Unit recording in the annular watermaze. Once complex spikes were identified during the screening trials, the rat received at least $3 \mathrm{hr}$ of rest to allow the stability of the recorded potentials to be checked. If the potentials were stable, the rat was given seven trial pairs at an interblock interval of $30 \mathrm{~min}$ in the watermaze. On standard trials, the platform was made available after the rat had swum one full circuit. For every fourth trial, a probe trial occurred in which the platform was kept in the unavailable position for the first $60 \mathrm{sec}$, regardless of the number of laps that the animal swam. Start positions varied between south, west, north, and east, except for the probe trials, in which the rat was always released $180^{\circ}$ off the platform position.

Before each test, the headstage was shielded by Vaseline. The cable was counterbalanced by a pulley and weight system, which allowed the rat to swim freely. On all trials, position and spike data were sampled in parallel. Recording was terminated at $120 \mathrm{sec}$. The data were stored on the hard disk and analyzed off-line. After swimming, the rat was placed under an infrared heating lamp.

Spike isolation and analysis. A "cluster-cutting" program allowed the spikes to be identified as belonging to individual cells according to voltage and temporal criteria (McNaughton et al., 1983a; O'Keefe and Recce, 1993; Harris et al., 2000). Clustering was performed manually in two-dimensional projections of the cluster space (Fig. 1). Pyramidal cells were identified and distinguished from interneurons by the duration of the extracellular action potential $(>0.3 \mathrm{msec}$ ), firing pattern (complex spikes), and low average firing rate in the watermaze (Ranck, 1973; Harris et al., 2000; Henze et al., 2000). Spikes within the same cluster were autocorrelated to check the quality of the isolation and to identify complex spikes (Fig. 1C), whereas spikes from adjacent pairs of clusters were cross-correlated to make sure that the early and late spikes of a complex-spike burst were not mistakenly assigned to different clusters (Fee et al., 1996; Quirk and Wilson, 1999; Harris et al., 2000).

Average firing rate was expressed as the total number of spikes divided by the total length of the recording period. The peak firing rate was found as follows. First, an array of $48 \times 48$ bins was placed over the sampling arena. The number of spikes in each bin was normalized by the dwell time of the rat within the space represented by the bin, and the values in this array were smoothed by replacing each value with the average of this value and those of the adjacent eight neighbors (those that had been visited). The peak rate was then taken as the maximum smoothed firing rate in any bin. The size of a place field was estimated by counting the number of adjacent bins with a firing rate of $>20 \%$ of the peak rate. Bins were also counted as adjacent when only their corners touched. A cluster of bins was considered a "place field" if $\geq 15$ adjacent bins exceeded this threshold.

All spike data reported from the water task are from the first $60 \mathrm{sec}$ of the probe trials, when the platform was unavailable to the rat. The firing rate distribution during these trials was examined by dividing the annular corridor into equally large segments $\left(6\right.$ segments of $60^{\circ}$ or 12 segments of $30^{\circ}$ ). We determined the firing rate of each cell in each segment and averaged these firing rates across probe trials. Field location was defined as the segment in which the cell had its maximum averaged firing rate. Unless otherwise specified, the data were sorted with respect to swim direction, and only those trial segments that were sampled in the preferred swim direction were retained.

The electrophysiological data were evaluated with nonparametric statistics (Hollander and Wolfe, 1999) because the firing-rate distributions were asymmetric and deviated significantly from normality. Median values are Hodges-Lehmann estimates. Variation is expressed by Tukey-Wilcoxon confidence intervals.

Spectral analysis. Fourier power spectra were calculated using Thompson's adaptive multitaper method, with NW equaling 4 (Percival and Walden, 1993). Time-frequency analysis (Fig. 1) was performed by wavelet transformation (Morlet continuous wavelet transform, $\omega_{0}=8$ ). Wavelet power was normalized by the signal variance. The wavelet "scales" were converted to the corresponding "harmonic frequencies" and linearized before plotting (Torrence and Compo, 1998).

Histology. The rats were killed with an overdose of Equithesin and perfused intracardially with saline and $4 \%$ formaldehyde. The brains were extracted and stored in formaldehyde, and frozen sections $(30 \mu \mathrm{m})$ were cut coronally, mounted, and stained with cresyl violet. All sections in the electrode area were retained. The sections were subsequently examined under a light microscope to identify the electrode traces.

Approvals. The experiments were conducted in accordance with na- 

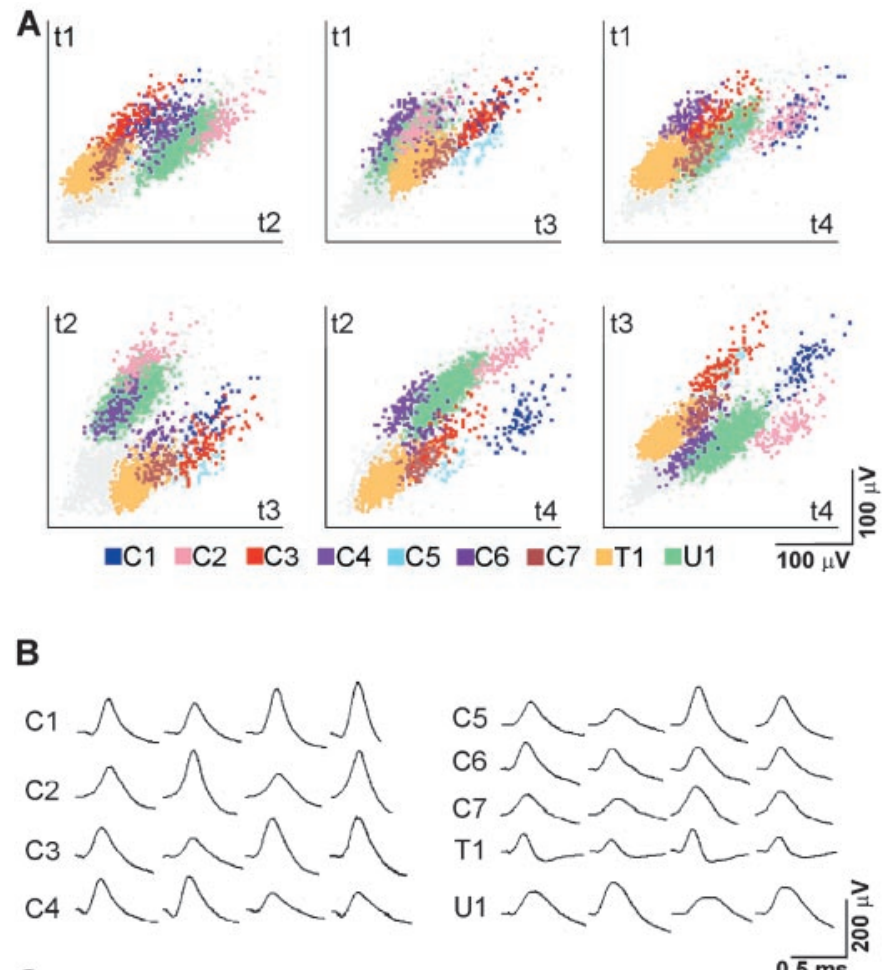

C

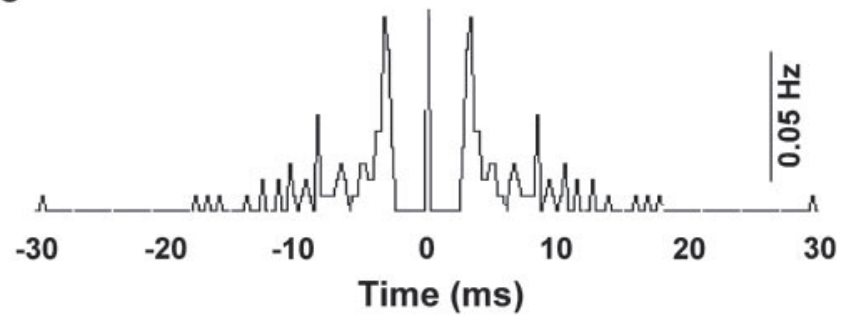

Figure 1. Isolation of single units during recording in water. $A$, Scatter diagrams illustrating the relationship between peak-to-peak amplitudes of spikes recorded simultaneously from electrodes $t 1$ to $t 4$ of one tetrode. All electrode combinations are shown. Each point represents one sampled signal. Nine clusters were isolated and assigned unique colors. Clusters $C 1-C 7$ were identified as complex spike cells, $T 1$ was a theta cell, and $U 1$ remained unclassified. $B$, Average waveforms of the units in $A$. $C$, Autocorrelation analysis of cell $C 2$ showing frequent interspike intervals of 3-5 msec (complex spikes) and absence of spikes at $<2 \mathrm{msec}$ (refractory period). These interspike intervals would be expected if the spikes arose from the same pyramidal cell. $C 1$ and $C 3-C 7$ had similar profiles and were also classified as pyramidal cells.

tional and European guidelines and approved by the National Animal Research Authority.

\section{RESULTS}

\section{Cell sample}

Units were isolated by a cluster-cutting procedure (Fig. 1A,B). We isolated a total of 139 hippocampal units in 13 rats, all with average firing rates of $>0.3 \mathrm{~Hz}$. The rats were tested both in water and in an open field. If a cell fired $>0.3 \mathrm{~Hz}$ in one task and $<0.3$ $\mathrm{Hz}$ in the other, it was included for analysis only in the former. Place-related firing was not used as a selection criterion. The mean number of isolated units recorded at one time was 7.2.

The units were categorized as pyramidal cells $(n=132)$ or interneurons $(n=7)$ depending on spike duration $(0.3-0.5$ vs $<0.3 \mathrm{msec}$ ), interspike intervals (Fig. $1 C$ ), and firing rates. The median peak-to-trough amplitudes $( \pm 95 \%$ confidence intervals) were $212 \pm 6 \mu \mathrm{V}$ (pyramidal cells) and $131 \pm 15 \mu \mathrm{V}$ (interneurons). The noise level during recording in the watermaze was $<30$ $\mu \mathrm{V}$. Movement artifacts were nearly absent during swimming in pretrained animals.

Examination of the electrode traces revealed the electrodes to be positioned in the CA1 layer of the dorsal hippocampus approximately in the middle between CA 3 and subiculum in all rats.

\section{Behavior}

The rats typically swam four to five circuits in the annular watermaze during the $60 \mathrm{sec}$ of a probe trial. Most animals swam in one direction only. In 12 of 13 rats, the preferred swim direction was the same on all probe trials (usually counterclockwise). One animal swam in the opposite direction on a single trial. All implanted rats swam slower and spent more time in the segment surrounding the platform than in the rest of the corridor on the probe trials (Fig. 2), indicating that they had formed a memory of where the platform used to be positioned. The spatial bias developed gradually during the course of training; there was no preference for the platform region on the first session (Fig. 2C).

\section{Constant platform location}

All analyses of neuronal activity in the water task were limited to the first $60 \mathrm{sec}$ of the probe trials. The platform was unavailable during this period. Trials in which the platform was raised after the first lap were not included in the present analyses.

Nine of the rats were trained with the platform at a constant position. In these animals, we recorded 80 units in the water task and 47 units in the open field, 23 of which were active in both environments. Seventy units in the water task and 44 units in the open field were spatially selective according to our criteria.

The distribution of average pyramidal cell-firing rates in the water task was asymmetric and skewed toward low values. The estimated median rate on the probe trials was $1.46 \mathrm{~Hz}$, which was slightly, but not significantly, higher than the estimated median rate of cells recorded in the same rats in the open field (MannWhitney $U$ test; $Z=1.8 ; p>0.05$ ) (Table 1 ). The median peak rate in the water corridor was $9.0 \mathrm{~Hz}$ (Table 1). The interneurons fired at an estimated median rate of $12.1 \mathrm{~Hz}$ and a peak rate of $25.9 \mathrm{~Hz}(n=7)$.

Most complex-spiking neurons with activity in the corridor (70\%) had stable single-peaked place fields (Fig. 3). Twenty percent had more than one firing field in at least one of the probe trials. Place fields were present in all parts of the corridor. On average, the fields covered $18.2 \%$ of the total search arena and were thus larger than place fields recorded in the same rats in the open field $(Z=6.7 ; p<0.001)$ (Table 1$)$. The interneurons fired all over the search arena, with low peak-to-average firing ratios.

The firing fields of the pyramidal cells were not homogeneously distributed during the probe trials. The number of units with firing fields in the platform segment was larger than in the other regions of the corridor (Fig. 4A). Twenty-seven pyramidal cells had firing fields in the platform segment; in the remaining segments, the number ranged from 8 to 14 (expected value, $13.3 ; \chi^{2}{ }_{5}=18.4$; two-sided test; $p<0.005)$. The second largest number (14) was in the segment preceding the platform segment. The number of cells with firing fields in the platform segment was significantly larger than expected by chance (binomial test; $Z=5.4$; $p<0.001$ ).

Firing rates in linear environments are modulated by the direction of movement of the animal (McNaughton et al., 1983b; Muller et al., 1994). Because the rats faced the nonpreferred direction more frequently in the platform segment $(21.7 \%$ of the 

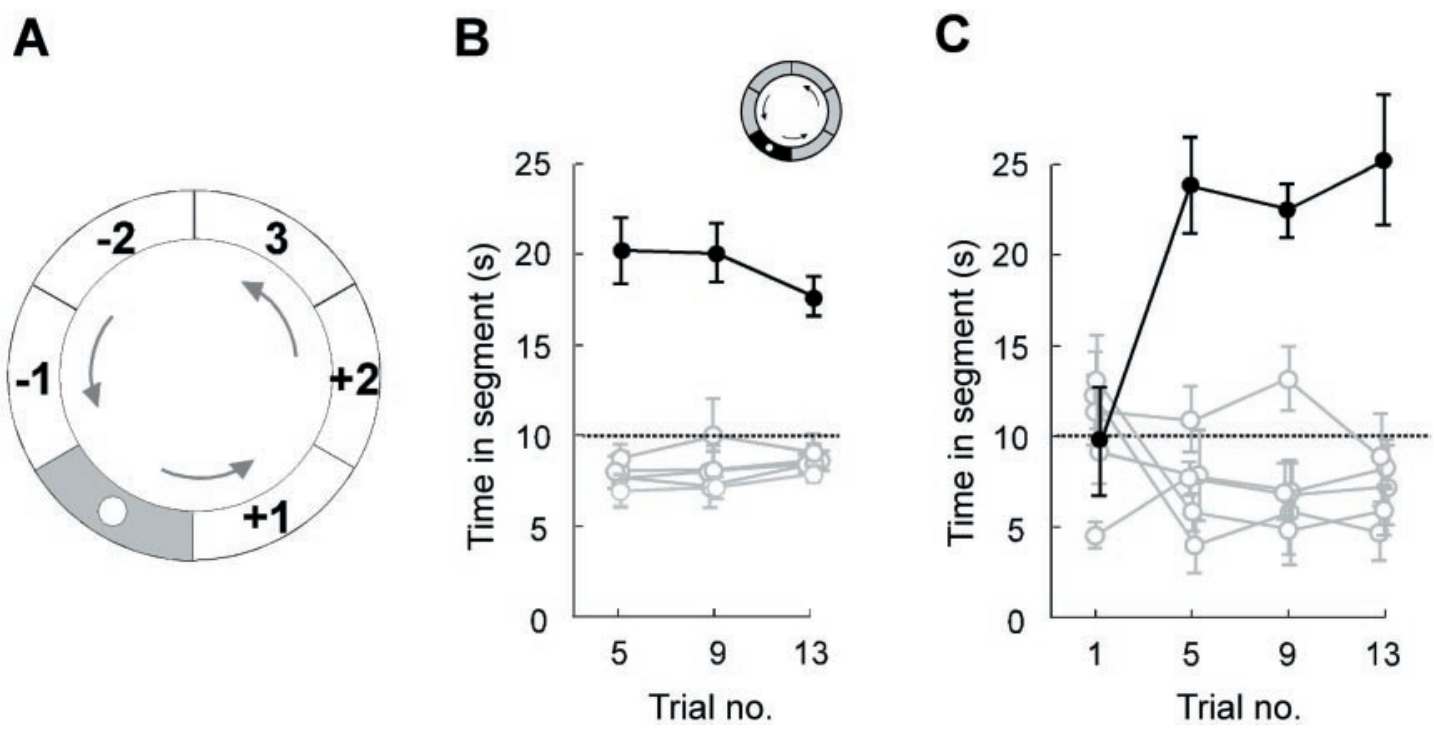

Figure 2. Spatial learning in the annular watermaze task. $A$, Division of the corridor into six equally large segments $\left(60^{\circ}\right.$ each), with the platform in the center of segment 0 . Segments were numbered with respect to preferred swim direction (arrows), so that segment -1 was entered before the platform segment and segment +1 was entered after the platform segment. B, Time in the platform segment ( filled circles) and each of the remaining segments (open circles) on three probe trials (means \pm SEM). Unit activity was recorded on all trials. The rats had received $>40$ trials in the corridor at this stage. $C$, Time distribution on four probe trials in rats that had not been exposed to the environment before. Preference for the platform segment developed gradually. Symbols are as described in $B$.

Table 1. Discharge characteristics of pyramidal cells during spatial and nonspatial training (estimated median values and 95\% confidence intervals)

\begin{tabular}{|c|c|c|c|c|}
\hline & $\begin{array}{l}\text { Average } \\
\text { firing rate }(\mathrm{Hz})\end{array}$ & $\begin{array}{l}\text { Peak } \\
\text { firing rate }(\mathrm{Hz})\end{array}$ & $\begin{array}{l}\text { Relative } \\
\text { field size }(\%)\end{array}$ & $\begin{array}{l}\text { Absolute field } \\
\text { size }\left(\mathrm{m}^{2}\right)\end{array}$ \\
\hline \multicolumn{5}{|c|}{ Rats trained with constant platform } \\
\hline Water corridor & $1.46(1.23-1.77)$ & $9.0(7.9-10.3)$ & $18.2(16.6-20.3)$ & 0.19 \\
\hline Open field & $1.16(0.93-1.44)$ & $13.3(11.2-15.6)$ & $7.8(6.8-9.6)$ & 0.08 \\
\hline \multicolumn{5}{|c|}{ Rats trained with variable platform } \\
\hline Water corridor & $1.29(0.97-1.62)$ & $10.7(8.4-13.8)$ & $15.6(13.2-17.9)$ & 0.17 \\
\hline Open field & $1.06(0.77-1.66)$ & $12.2(9.8-15.7)$ & $8.3(5.5-13.5)$ & 0.08 \\
\hline
\end{tabular}

swim time) than in the other segments (7-17\%), more cells could have been detected at the goal location simply as a result of better bidirectional sampling. To control for this possibility, we sorted the data with regard to swim direction and retained only those trial fragments that were sampled in the preferred direction of movement ( $87.6 \%$ of the total data set). The sorting procedure did not attenuate the over-representation of the platform segment. The number of cells with peak activity in the goal segment was now 24 compared with between 9 and 14 in the other segments. Again, the second largest number (14) was in the segment preceding the platform segment (Fig. 4B). Statistical analysis showed that the distribution of the unidirectional data remained nonuniform $\left(\chi^{2}{ }_{5}=11.7\right.$; two-sided test; $\left.p<0.05\right)$ and that the number of cells with firing fields in the goal segment was larger than expected by chance (binomial test; $Z=4.4 ; p<$ $0.001)$. The number of cells with fields in the preceding segment was not significantly larger than in the succeeding segment in this analysis (binomial test; $Z=0.9$ ).

The accumulation of firing fields in the platform segment was maintained in a separate analysis of those cells that had single fields according to our criteria (platform segment, 20 cells; nontarget segments, from six to eight cells). The distribution was nonuniform $\left(\chi_{5}^{2}=15.1\right.$; two-sided test; $\left.p<0.01\right)$, with more fields in the platform segment than expected by chance (binomial test; $Z=3.8 ; p<0.001)$. Cells with no distinct field or with multiple fields were not associated with any particular segment of the corridor (no field, one cell in the platform segment and zero to three cells in the other segments; multiple fields, three cells in the platform segment and one to five cells in the other segments).

To determine how exactly the accumulation of firing fields corresponded to the location of the platform, we doubled the number of segments. Segment boundaries were defined so that the platform position was in the middle of one of the segments. After directional sorting, 19 of the 80 cells exhibited peak activity within the $30^{\circ}$ of arc that now defined the platform segment (Fig. $4 C)$. The corresponding numbers in the remaining 11 segments ranged from three to nine, with nine in the segment that preceded the platform position and three in the segment that succeeded it (the others ranged from four to seven). The distribution was clearly nonuniform $\left(\chi_{11}^{2}=29.2\right.$; two-sided test; $\left.p<0.001\right)$, with a sharp increase in the number of cells that had firing fields just where the platform used to be located. The increase in the number of fields in the platform segment was highly significant (binomial test; $Z=5.0 ; p<0.001$ ). In addition, with the increased resolution added by finer segmentation, there was now a larger 

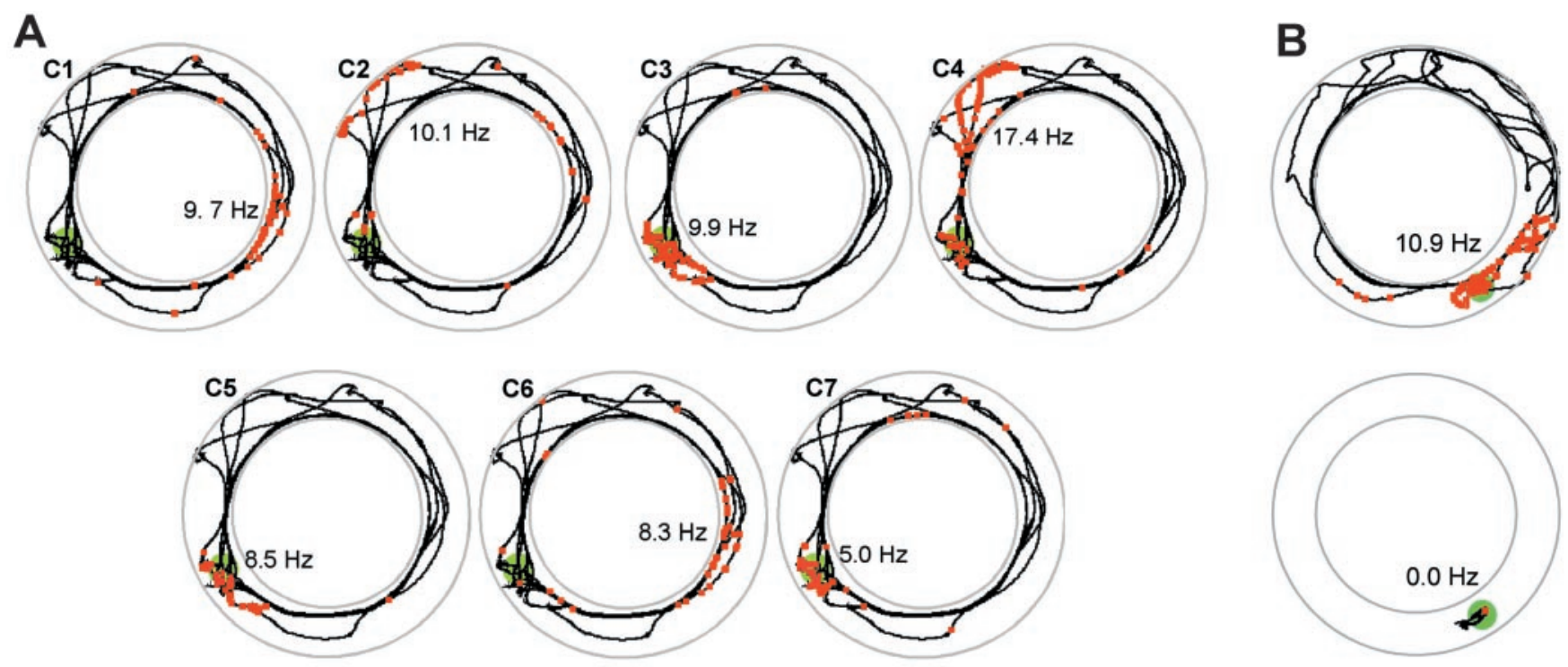

Figure 3. Place fields in the annular watermaze. A, Firing correlates of seven pyramidal cells (Fig. 1, C1-C7) during the first 60 sec of a probe trial in the annular watermaze. The platform was unavailable to the rat during this period. The rat had been trained with the platform set SW ( green). Spikes (red squares) are superimposed on the swim path (black). Numbers indicate peak firing rates and location of peak activity. B, Firing in the platform area before and after escape on the platform. The cell had a field at the goal location during swimming $(0-81$ sec $)$ but ceased firing after the rat climbed onto the platform $(81-100 \mathrm{sec})$. Symbols are as described in $A$.
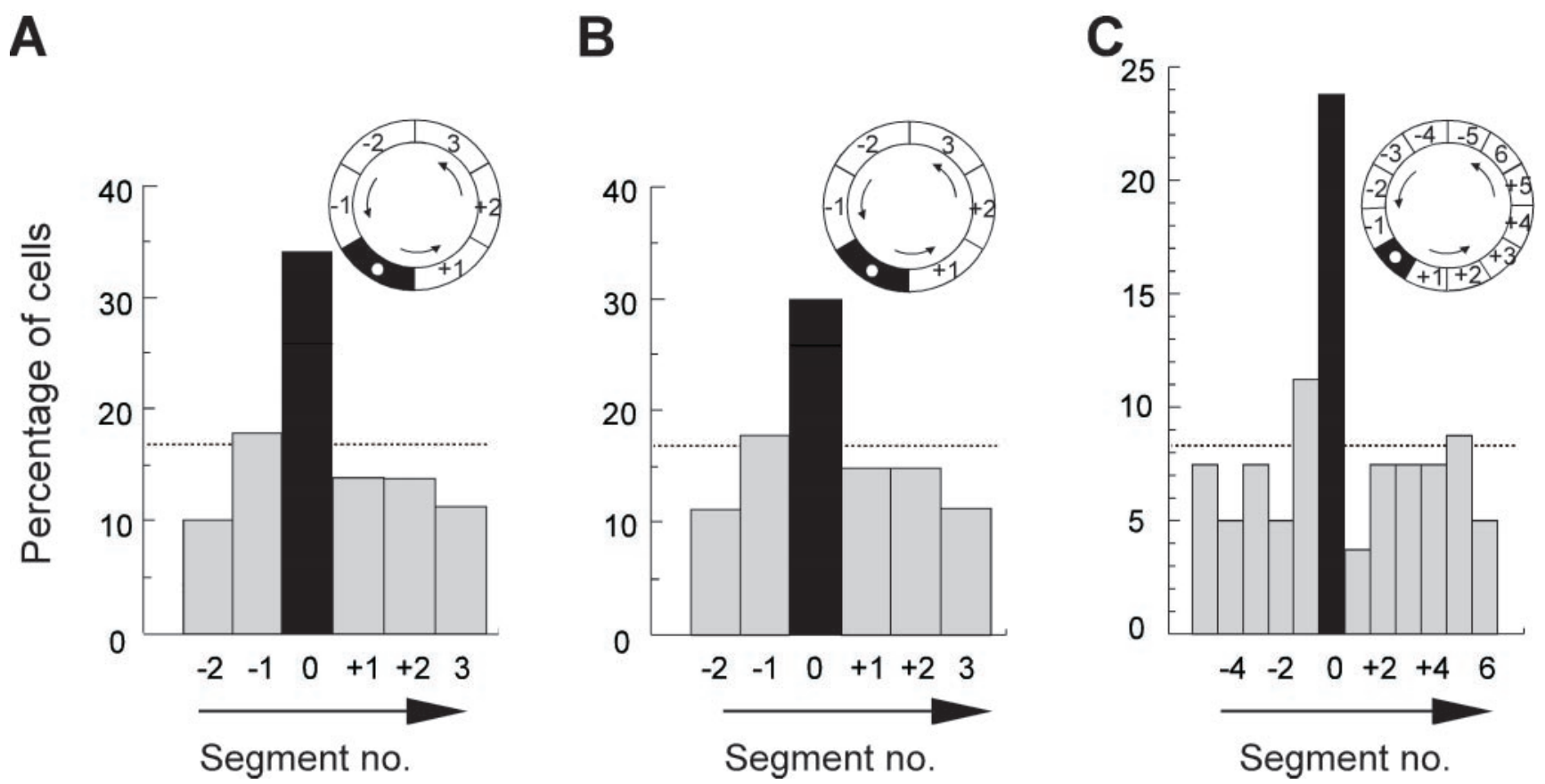

Figure 4. Distribution of firing fields after training with a constant platform location. $A$, Percentage of firing fields in each $60^{\circ}$ segment of the corridor ( 80 cells; average of 3 probe tests). Field location was defined as the segment with the maximal averaged firing rate. Firing fields accumulated in the platform segment (segment 0, black). The chance level was at $16.7 \%$. Inset, Diagram of the corridor. Arrows indicate swim direction. B, Percentage of firing fields in each $60^{\circ}$ segment after directional sorting (same trials and same symbols as described in $A$ ). Only data sampled during swimming in the preferred direction are retained. $C$, Percentage of firing fields in segments of $30^{\circ}$ after directional sorting. The platform was in the middle of segment 0 .

number of units with fields in the segment preceding the goal than in the segment after it (binomial test; $Z=2.5 ; p=0.01$ ).

The bias was independent of the actual position of the platform in the room. Fifteen of the 80 cells in our sample were recorded with a NE platform, 15 with a NW platform, 24 with a SW platform, and 26 with a SE platform. In all four cases, the largest percentage of place fields was found in the platform segment $\left(30^{\circ}\right)$. The respective percentages were $33.3 \%(\mathrm{NE}), 20.0 \%$ (NW), $29.2 \%(\mathrm{SW})$, and $15.4 \%$ (SE). The chance level was at $8.3 \%$.

Most cells with peak activity at the platform position during the probe trial (12 of 19 units) became less active as the rat entered the platform. In eight units $(42 \%)$, the firing rate in the goal segment was reduced to $<30 \%$ of the rate at this location during 
swimming. One unit almost stopped firing (the firing rate decreased from 5.6 to $0.07 \mathrm{~Hz}$ ) (Fig. 3B). However, there were also cells that maintained or increased their activity after the rat climbed the platform $(n=7)$.

The size of place fields with peaks within the platform segment was comparable with that of fields in other segments. Place fields in the platform segment covered $18.4 \%(15.3-22.2 \%)$ of the visited area, whereas the fields of the remaining cells covered $18.2 \%(16.4-20.6 \%$ ) (estimated medians and 95\% confidence intervals, respectively). The background firing of cells with firing fields in the goal segment was not different from that of cells with fields at other places ( 0.49 vs $0.50 \%$ of average rate; background defined as $>45^{\circ}$ off the center of the segment with peak activity).

\section{Variable platform location}

In four rats, the platform was varied according to a pseudorandom schedule. We isolated 28 cells in the water task and 17 in the open field in these animals. Ten of the cells were active in both conditions. Twenty-three of the cells in the water task and 15 cells in the open field satisfied the criteria for spatial selectivity.

Average and peak firing rates during the probe trials were not significantly different from those recorded in the same rats in the open field or those recorded in different rats in the constant platform condition (Table 1). There was no significant effect of training condition on the shape of the firing fields in the water task. The fields were not sharper when the platform location was constant compared with when the location was varied randomly (Fig. 5). The ratios between in-field and background firing rates were 12.9 and 11.1, respectively (estimated median values; field defined as the $30^{\circ}$ segment with peak activity; background defined as all areas $>45^{\circ}$ off the center of the field segment; MannWhitney $U$ test; $Z=1.0 ; p>0.30$ ).

Place fields were also present in all regions of the corridor when the platform location was varied. The fields did not cluster in any particular region (Fig. 6). When we defined the segments by room coordinates (relative to the external cues), the number of units with firing fields in each segment ranged from three to six after directional sorting (expected value, $4.7 ; \chi^{2}{ }_{5}=1.88 ; p>0.50$ ) (Fig. 6A). When the segments were defined relative to the position of the platform on the preceding trial, six cells had firing fields in the previous platform segment, whereas the number of fields in the other segments was between three and six $\left(\chi^{2}{ }_{5}=\right.$ $1.88 ; p>0.50$ ) (Fig. 6B).

\section{Place fields or instantaneous behavior?}

Enhanced activity during swimming in the platform area could reflect changes in state or behavior. First, silent cells frequently turn on during large-amplitude irregular activity (LIA) in the hippocampal EEG (Thompson and Best, 1989; Buzsáki et al., 1992). Enhanced firing at the platform location could reflect brief epochs of LIA. LIA is associated with sharp waves of 40-100 msec duration (Buzsáki et al., 1983). These are positive (reversed) in the pyramidal cell layer (Buzsáki et al., 1983) and should appear as increases in power between 10 and $25 \mathrm{~Hz}$. There was no change in this frequency band as the rat swam over the platform on the probe trials (Fig. 7). Theta oscillations were maintained throughout the trial, even when the rat slowed down in the target area. Fourier power spectra showed a sharp peak in the theta frequency band $(6-9 \mathrm{~Hz})$ both inside and outside the platform segment (estimated medians, 0.175 and $0.177 \mathrm{mV}^{2}$, respectively). The difference was not significant (robust $R$ regression; Jaeckel-Hettmansperger; $\left.F_{(1,15)}=1.8 ; p=0.20\right)$.

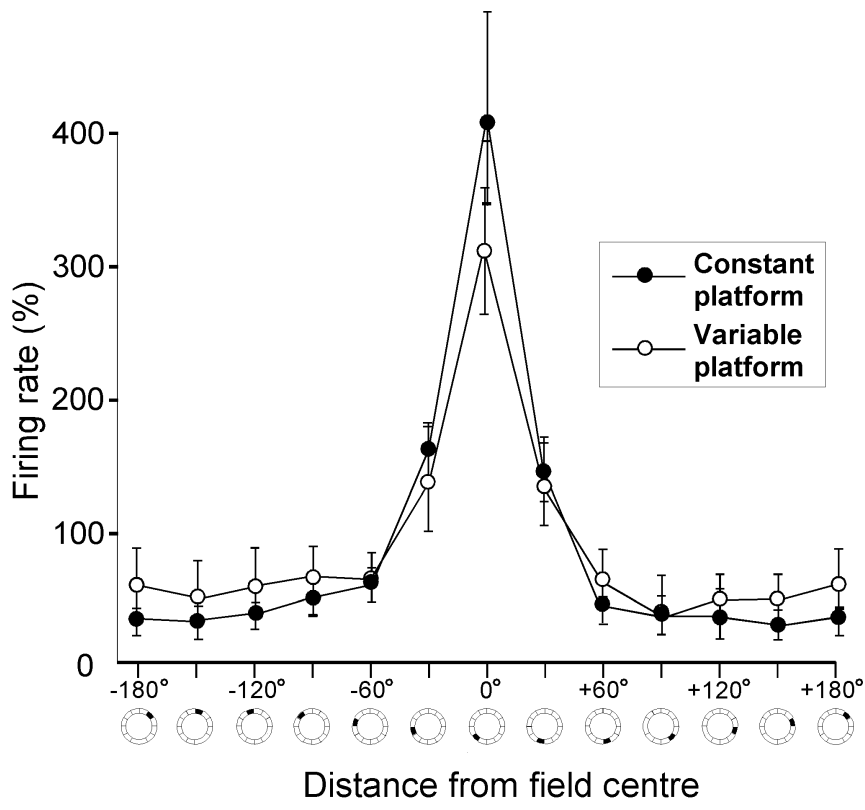

Figure 5. Similar shape of hippocampal place fields after training with a constant or a variable platform location. The diagram shows unidirectional median firing rates (Hodges-Lehmann estimates \pm upper and lower $95 \%$ Tukey-Wilcoxon confidence intervals) as a function of distance from the segment in which the cell fired at the highest rate $\left(0^{\circ}\right)$. Segments cover $30^{\circ}$ of arc each.

Second, the recorded neurons may have been more active in the target region simply because the rats swam more slowly there. However, slow swimming was not accompanied by enhanced firing when it occurred outside the platform segment (Fig. 7A, right). To quantify the relationship between annular speed and firing rate, we used data from animals trained with a variable platform location and calculated mean firing rate above and below median swim velocity with kernel density estimation (essentially as in McNaughton et al., 1983b). The weighted geometric mean of the ratio (above/below median) was 0.9 (95\% bootstrap confidence intervals of 0.2-4.5), indicating no difference in firing rates.

Third, firing rates may have increased in the platform segment because the angular velocity of the rat increased (Wiener et al., 1989). However, firing rates were not elevated when the rat turned outside the platform segment (Fig. 7A, right). We divided the swim paths into consecutive, staggered segments and calculated how much the length of each segment deviated from the shortest possible line between the start and end points of the segment. Mean firing rates above and below the median were calculated for the variable platform data in the same way as for linear speed. The weighted geometric mean of the ratio (above/ below median) was 1.0 (95\% bootstrap confidence intervals of 0.2-6.5), indicating that firing rates did not increase as a function of frequent turning per se.

A fourth caveat is that enhanced activity near the platform could reflect more efficient sampling of place fields. Because of deviations from strict clockwise or counterclockwise movement, the area visited was slightly larger in the platform segment than elsewhere (40 vs 32-35 pixels; average values of three probe tests; segments of $\left.60^{\circ}\right)$. We analyzed a subset of the data, using from each rat only the trial with the poorest coverage in the platform segment. This eliminated the differences in coverage (34.4 vs 31-39 pixels) but failed to change the disproportionately large 


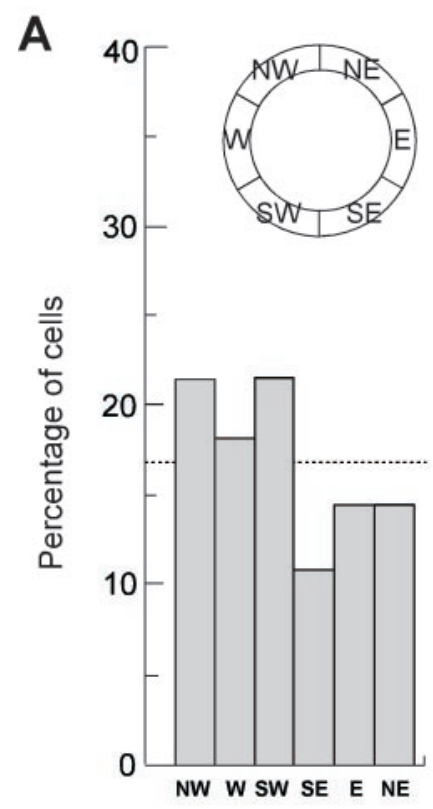

Segment no.

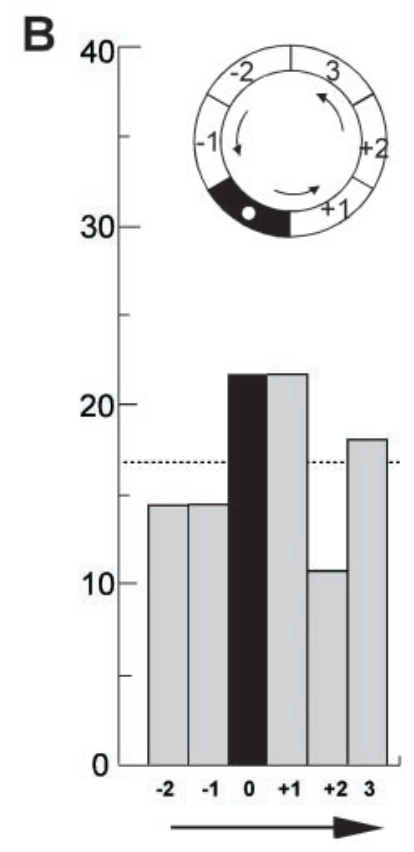

Segment no.
Figure 6. Distribution of firing fields after training with a variable platform location. $A$, Segments $\left(60^{\circ}\right)$ defined relative to external cues (room frame). $B$, Segments defined relative to platform location on the preceding trial (platform in segment 0 ). Symbols are as described in $A$ and Figure 4.

number of place fields in the platform segment compared with the other segments (23 vs 4-13 units, respectively; $\chi^{2}$ test, $\chi^{2}{ }_{5}=14.6$; two-sided test, $p=0.01$; binomial test, $Z=3.4$; two-sided test, $p<0.001)$. Similar results were obtained with $30^{\circ}$ segments (15 vs 2-8 units; $Z=3.9 ; p<0.001)$.

\section{DISCUSSION}

The main finding is that spatial training in the annular watermaze led to a nonrandom distribution of hippocampal place fields. The area around the platform was over-represented, despite the fact that the escape platform was unavailable. The effect appeared only in animals that expected to find the platform at that location.

\section{Place fields or behavioral modulation?}

Although position is the primary determinant of firing in hippocampal pyramidal cells, firing rates are modulated by the instantaneous behavior of the animal. We were concerned that the hippocampal theta activity was interrupted by brief periods of LIA as the animal swam over the platform. During LIA, the out-of-field firing rate may increase and previously silent cells may start to fire (Thompson and Best, 1989; Buzsáki et al., 1992). However, there was no reduction in the power within the theta frequency range, and there was no enhancement at frequencies that are expected to increase during sharp waves. A second concern was the linear and angular speed of the animal, which changed over the platform. There was no relationship between speed and firing rate. Previous research has shown that hippocampal firing rates decrease rather than increase during slow movement (McNaughton et al., 1983b; Wiener et al., 1989; Czurkó et al., 1999). Finally, the disproportionate number of firing fields in the platform area was not an artifact of better coverage of the platform segment, and the effect was not attenuated when the preferred swim direction was analyzed separately.
Thus, none of the examined behavioral changes accounted for the clustering of place fields in the platform region.

\section{Representation of the goal area}

The increased number of place fields in the platform zone challenges the idea that place fields are evenly distributed. There are several possible reasons why firing fields were more abundant near the target. One relates to familiarity. The rat spent more time in the platform segment and might be more attentive as it passes through this area than at other places, and so more cells may have been recruited to represent this location. However, prolonged exposure does not appear to change the number of cells with place fields in a given environment. Place fields are usually established within the first few minutes that a rat spends in a novel arena (Hill, 1978; Bostock et al., 1991; Wilson and McNaughton, 1993) and change little thereafter (Muller and Kubie, 1987; Thompson and Best, 1990). Because all regions of the swim corridor had been visited at least once during each of $>40$ pretraining trials, the off-target segments were probably not under-represented because of insufficient exposure.

Firing fields may accumulate at some places because these places contain particularly salient stimuli. In enclosed environments, place fields appear to be more common near edges and walls than in the center (Muller et al., 1987; Hetherington and Shapiro, 1997). Peripheral stimuli exert strong and distancedependent control over the activity of place cells (O'Keefe and Burgess, 1996), but few place fields are influenced by landmarks inside the experimental arena (Cressant et al., 1997). It is unlikely that such geometrical constraints are responsible for the uneven distribution in the annular water task. The shape of the corridor was homogeneous, and the only salient proximal stimulus (the platform) was absent during the reported trials.

However, firing fields may also reflect the behavioral significance of stimuli at particular locations. Previous research has shown that place fields tend to accumulate at reward locations when these consist of prominent landmarks (Eichenbaum et al., 1987; Breese et al., 1989; Kobayashi et al., 1997), but it remains elusive whether the location-specific firing is controlled by the sensory or the incentive-related properties of the goal object. Firing fields sometimes follow salient stimuli, even when these are not goal objects (Young et al., 1994; Wood et al., 1999), suggesting that, in some cells, the sensory characteristics of the goal may provide sufficient input to control firing in a place-independent manner (Gothard et al., 1996). Attempts to find nonsensory goal-related place activity have so far been unsuccessful (Speakman and O'Keefe, 1990).

The present experiment differs from previous ones in that the goal object was completely unmarked. All analyses were limited to the first minute of probe trials when the platform was unavailable to the rat's senses, implying that the sensory environment was identical for rats trained with the platform at different locations. Despite this fact, the goal location attracted a disproportionate number of firing fields, regardless of its location. The only difference between locations in which fields accumulated and locations in which they did not was whether the animal expected to find the platform there. The fact that place fields were more abundant in the segment preceding the goal than in the succeeding segment further suggests that expectancy may have contributed to the firing in the platform area. This possibility is consistent with data showing that activity in the place field is frequently influenced by where the animal comes from or is going next (Frank et al., 2000; Wood et al., 2000). 

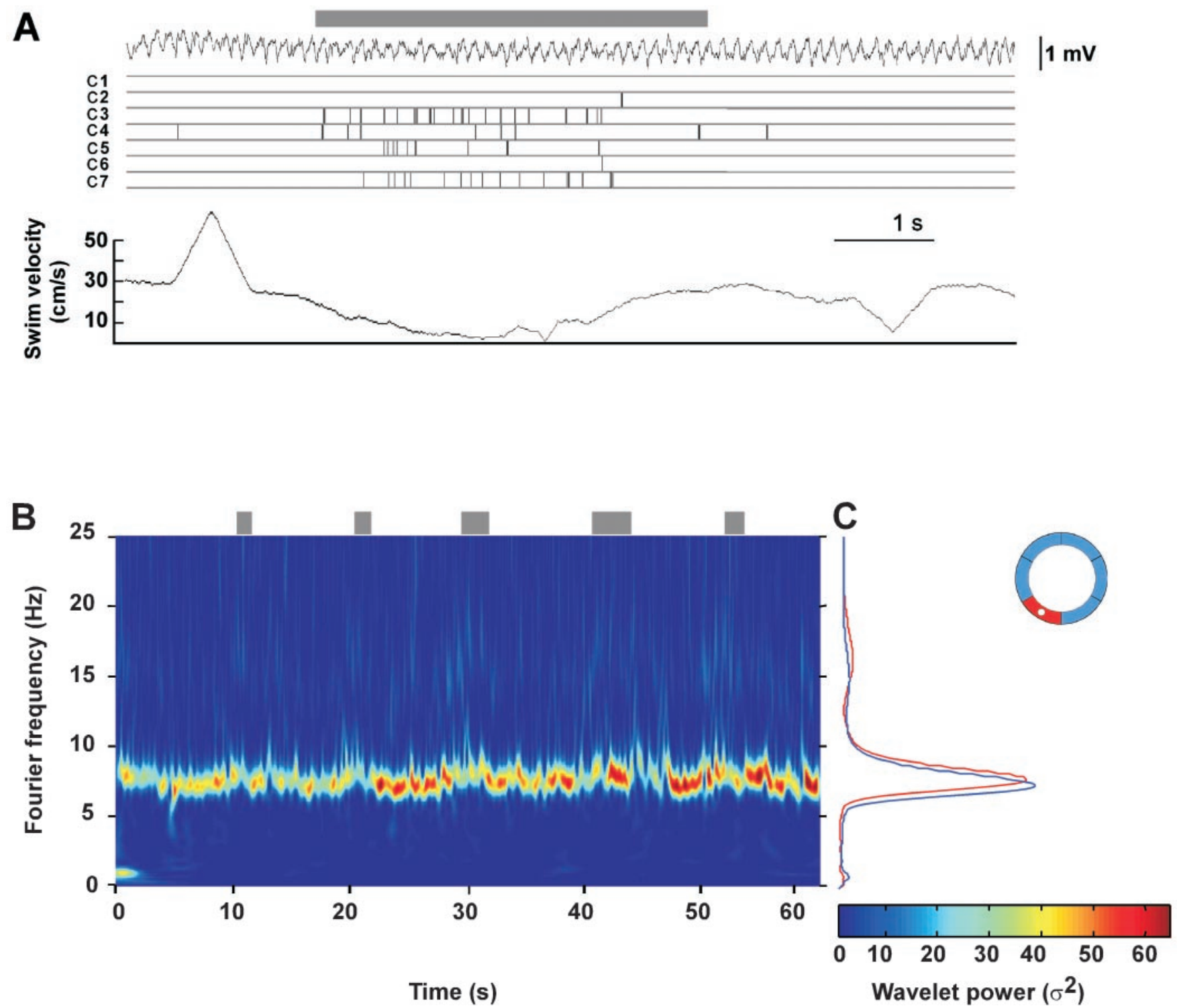

Figure 7. Independence of platform-related firing from instantaneous behavior (same cells as in Figs. 1 and 3). A, Hippocampal EEG (top), activity of pyramidal cells $C 1-C 7$ (middle), and swim speed (bottom) during $10 \mathrm{sec}$ of clockwise swimming from SE toward NE. Swimming over the platform ( \pm 10 $\mathrm{cm}$ ) is indicated (horizontal gray bar). As the rat passed over the target, there was a significant increase in the activity of several, but not all, recorded units (not C1, C2, and C6). Swim speed decreased, but theta oscillations were maintained. Reduced speed (turning) outside the platform region (right) was not accompanied by increased firing. $B$, Multiresolution color-coded spectrogram of hippocampal EEG during the same probe trial. Note the maintenance of theta activity and the absence of other frequencies in the $0-25 \mathrm{~Hz}$ range as the animal searched over the platform (horizontal gray bars). Low-frequency waves at $0-1$ and 59-60 sec reflect electrical noise during release and platform elevation, respectively. $C$, Time-averaged wavelet spectra of EEG sampled inside (red) and outside (blue) the platform segment. The frequency axis is as described in $B$.

It is possible that some of the cells with firing fields in the platform segment are identical to the "misplace cells" previously reported to respond to the absence of expected objects (Ranck, 1973; O'Keefe, 1976). A few units clearly fired less after the rat had found the platform. The effect was sometimes so strong (Fig. $3 B$ ) that it cannot only be attributed to changes in behavior or hippocampal EEG. However, there were other cells that maintained a high firing rate after the rat escaped onto the platform, suggesting that the population of cells with firing fields in the target area may be functionally heterogeneous.

The extent to which cells with firing fields at the platform location represent the goal as such can only be established conclusively by moving the platform to a new position and observing whether the firing follows. Preliminary data suggest that some cells with platform-related activity exhibit a partial shift in firing after reversal of the platform position (Moser et al., 1999), but the sample was too small to determine whether the shift was specific for these cells or reflected a more general remapping within the ensemble. The possibility of nonselective remapping, as well as functional heterogeneity among cells with firing fields at the remembered goal location, suggests that multitetrode recording from large ensembles may be necessary to demonstrate goalrelated activity specifically and unequivocally.

\section{Experience-dependent plasticity and memory}

Previous studies suggest that hippocampal place cells not only respond to immediate sensory information but also express information stored in the animal's memory. First, when a rat is kept in 
the recording apparatus, place cells continue to fire after the surrounding landmarks are concealed (Muller and Kubie, 1987; O'Keefe and Speakman, 1987; Quirk et al., 1990). Second, rats develop different hippocampal representations of two visually identical parts of an environment that probably are distinguishable only on the basis of recent memory (Sharp et al., 1990; Skaggs and McNaughton, 1998; Tanila, 1999). Third, some hippocampal place cells (misplace cells) respond primarily during mismatches between what an animal is likely to expect at a place and what it actually experiences there (Ranck, 1973; O'Keefe, 1976). Finally, some hippocampal neurons appear to respond specifically during recall of task-relevant information, such as during the presentation of the conditioned stimulus in a classical conditioning task (Berger et al., 1976) and in the matching phase of a delayed-matching short-term memory task (Wood et al., 1999). Collectively, these studies suggest that hippocampal neurons can express information that is retrieved from memory. The contribution of direct sensory input is often hard to eliminate entirely, however. Removing distal cues does not cancel the contribution of proprioceptive or kinesthetic stimuli, and comparing activity in two versions of the same environment does not guarantee that the animal perceives the environments as identical. In the present study, place fields accumulated at the goal, even when the goal object was completely unavailable to any of the rat's sensory systems. There was probably no other way that the platform could influence firing than through an association between particular landmarks and the remembered platform.

The abundance of place fields in the goal area may have contributed to the maintenance of spatial memory in the annular task. The number of goal-associated place fields was increased only when the animal knew where the platform was located. However, was this plasticity necessary for the performance of the animal? Many tasks used to demonstrate changes in hippocampal firing during recall are hippocampal-independent (Schmaltz and Theios, 1972; Dudchenko et al., 2000). Successful performance in the annular watermaze task does require an intact hippocampus (S. Hollup, K. G. Kjelstrup, J. Hoff, M. B. Moser, and E. I. Moser, unpublished observations). Rats with hippocampal lesions learn to swim in laps but fail to slow down when they pass the platform location on the probe trials, suggesting that they do not recognize the platform region. It will be important in future research to determine whether the observed plasticity in the ensemble representation of the goal location represents an essential link in the chain of events culminating in recognition of this area.

\section{REFERENCES}

Berger TW, Alger B, Thompson RF (1976) Neuronal substrate of classical conditioning in the hippocampus. Science 192:483-485.

Bontempi B, Laurent-Demir C, Destrade C, Jaffard R (1999) Timedependent reorganization of brain circuitry underlying long-term memory storage. Nature 400:671-675.

Bostock E, Muller RU, Kubie JL (1991) Experience-dependent modifications of hippocampal place cell firing. Hippocampus 1:193-205.

Breese CR, Hampson RE, Deadwyler SA (1989) Hippocampal place cells: stereotypy and plasticity. J Neurosci 9:1097-1111.

Buzsáki G, Leung LWS, Vanderwolf CH (1983) Cellular bases of hippocampal EEG in the behaving rat. Brain Res Rev 6:139-171.

Buzsáki G, Horvath Z, Urioste R, Hetke J, Wise K (1992) Highfrequency network oscillation in the hippocampus. Science 256:1025-1027.

Cressant A, Muller RU, Poucet B (1997) Failure of centrally placed objects to control the firing fields of hippocampal place cells. J Neurosci 17:2531-2542.

Czurkó A, Hirase H, Csicsvari J, Buzsáki G (1999) Sustained activation of hippocampal pyramidal cells by "space clamping" in a running wheel. Eur J Neurosci 11:344-352.

Dudchenko PA, Wood ER, Eichenbaum H (2000) Neurotoxic hippocampal lesions have no effect on odor span and little effect on odor recognition memory but produce significant impairments on spatial span, recognition, and alternation. J Neurosci 20:2964-2977.

Eichenbaum H, Kuperstein M, Fagan A, Nagode J (1987) Cue-sampling and goal-approach correlates of hippocampal unit activity in rats performing an odor-discrimination task. J Neurosci 7:716-732.

Eichenbaum H, Dudchenko P, Wood E, Shapiro M, Tanila H (1999) The hippocampus, memory, and place cells: is it spatial memory or a memory space? Neuron 23:209-226.

Fee MS, Mitra PP, Kleinfeld D (1996) Automatic sorting of multiple unit neuronal signals in the presence of anisotropic and non-Gaussian variability. J Neurosci Methods 69:175-188.

Frank LM, Brown EN, Wilson M (2000) Trajectory encoding in the hippocampus and entorhinal cortex. Neuron 27:169-178.

Gothard KM, Skaggs WE, Moore KM, McNaughton BL (1996) Binding of hippocampal CA1 neural activity to multiple reference frames in a landmark-based navigation task. J Neurosci 16:823-835.

Harris KD, Henze DA, Csicsvari J, Hirase H, Buzsáki G (2000) Accuracy of tetrode spike separation as determined by simultaneous intracellular and extracellular measurements. J Neurophysiol 84:401-414.

Henze DA, Borhegyi Z, Csicsvari J, Mamiya A, Harris KD, Buzsáki G (2000) Intracellular features predicted by extracellular recordings in the hippocampus in vivo. J Neurophysiol 84:390-400.

Hetherington PA, Shapiro ML (1997) Hippocampal place fields are altered by the removal of single visual cues in a distance-dependent manner. Behav Neurosci 111:20-34.

Hill AJ (1978) First occurrence of hippocampal spatial firing in a new environment. Exp Neurol 62:282-297.

Hollander M, Wolfe D (1999) Nonparametric statistical methods, Ed 2. New York: Wiley.

Kobayashi T, Nishijo H, Fukuda M, Bures J, Ono T (1997) Taskdependent representations in rat hippocampal place neurons. J Neurophysiol 78:597-613.

Maguire EA, Frackowiak RSJ, Frith CD (1997) Recalling routes around London: activation of the right hippocampus in taxi drivers. J Neurosci 17:7103-7110.

Maguire EA, Burgess N, Donnett JG, Frackowiak RS, Frith CD, O'Keefe J (1998) Knowing where and getting there: a human navigation network. Science 280:921-924.

McNaughton BL, O'Keefe J, Barnes CA (1983a) The stereotrode: a new technique for simultaneous isolation of several single units in the central nervous system from multiple unit records. J Neurosci Methods 8:391-397.

McNaughton BL, Barnes CA, O'Keefe J (1983b) The contributions of position, direction, and velocity to single unit activity in the hippocampus of freely-moving rats. Exp Brain Res 52:41-49.

Morris RGM, Frey U (1997) Hippocampal synaptic plasticity: role in spatial learning or the automatic recording of attended experience? Philos Trans R Soc Lond B Biol Sci 352:1489-1503.

Morris RGM, Garrud P, Rawlins JNP, O'Keefe J (1982) Place navigation impaired in rats with hippocampal lesions. Nature 297:681-683.

Morris RGM, Schenk F, Tweedie F, Jarrard LE (1990) Ibotenate lesions of hippocampus and/or subiculum: dissociating components of allocentric spatial learning. Eur J Neurosci 2:1016-1028.

Moser EI, Hollup SA, Donnett JG, Moser MB (1999) Dissociation of place and goal in CA1 pyramidal cells in a water-maze reversal task. Soc Neurosci Abstr 25:649.6.

Muller RU, Kubie JL (1987) The effects of changes in the environment on the spatial firing of hippocampal complex-spike cells. J Neurosci 7:1951-1968.

Muller RU, Kubie JL, Ranck JB (1987) Spatial firing patterns of hippocampal complex-spike cells in a fixed environment. J Neurosci 7:1935-1950.

Muller RU, Bostock E, Taube JS, Kubie JL (1994) On the directional firing properties of hippocampal place cells. J Neurosci 14:7235-7251.

O'Keefe J (1976) Place units in the hippocampus of the freely moving rat. Exp Neurol 51:78-109.

O'Keefe J, Burgess N (1996) Geometric determinants of the place fields of hippocampal neurons. Nature 381:425-428.

O'Keefe J, Nadel L (1978) The hippocampus as a cognitive map. Oxford: Clarendon.

O'Keefe J, Recce ML (1993) Phase relationship between hippocampal place units and the EEG theta rhythm. Hippocampus 3:317-330.

O'Keefe J, Speakman A (1987) Single unit activity in the hippocampus during a spatial memory task. Exp Brain Res 68:1-27.

Olton DS, Walker JA, Gage FH (1978) Hippocampal connections and spatial discrimination. Brain Res 139:295-308.

Percival DB, Walden AT (1993) Spectral analysis for physical applications: multitaper and conventional univariate techniques. Cambridge: Cambridge UP.

Quirk MC, Wilson MA (1999) Interaction between spike waveform classification and temporal sequence detection. J Neurosci Methods 94:41-52.

Quirk GJ, Muller RU, Kubie JL (1990) The firing of hippocampal place cells in the dark depends on the rat's recent experience. J Neurosci 10:2008-2017. 
Ranck Jr JB (1973) Studies on single neurons in dorsal hippocampal formation and septum in unrestrained rats. I. Behavioral correlates and firing repertoires. Exp Neurol 41:461-531.

Schmaltz LW, Theios J (1972) Acquisition and extinction of a classically conditioned response in hippocampectomized rabbits (Oryctolagus cuniculus). J Comp Physiol Psychol 79:328-333.

Sharp PE, Kubie JL, Muller RU (1990) Firing properties of hippocampal neurons in a visually symmetrical environment: contributions of multiple sensory cues and mnemonic processes. J Neurosci 10:3093-3105.

Skaggs WE, McNaughton BL (1998) Spatial firing properties of hippocampal CA1 populations in an environment containing two visually identical regions. J Neurosci 18:8455-8466.

Speakman A, O'Keefe J (1990) Hippocampal complex spike cells do not change their place fields if the goal is moved within a cue-controlled environment. Eur J Neurosci 2:544-555.

Squire LR (1992) Memory and the hippocampus: a synthesis from findings with rats, monkeys, and humans. Psychol Rev 99:195-231.

Tanila H (1999) Hippocampal place cells can develop distinct representations of two visually identical environments. Hippocampus 9:235-246.
Thompson LT, Best PJ (1989) Place cells and silent cells in the hippocampus of freely-behaving rats. J Neurosci 9:2382-2390.

Thompson LT, Best PJ (1990) Long-term stability of the place-field activity of single units recorded from the dorsal hippocampus of freely behaving rats. Brain Res 509:299-308.

Torrence C, Compo GP (1998) A practical guide to wavelet analysis. Bull Am Meteorol Soc 79:61-78.

Wiener SI, Paul CA, Eichenbaum H (1989) Spatial and behavioral correlates of hippocampal neuronal activity. J Neurosci 9:2737-2763.

Wilson MA, McNaughton BL (1993) Dynamics of the hippocampal ensemble code for space. Science 261:1055-1058.

Wood ER, Dudchenko PA, Eichenbaum H (1999) The global record of memory in hippocampal neuronal activity. Nature 397:613-616.

Wood ER, Dudchenko PA, Robitsek RJ, Eichenbaum H (2000) Hippocampal neurons encode information about different types of memory episodes occurring in the same location. Neuron 27:623-633.

Young BJ, Fox GD, Eichenbaum H (1994) Correlates of hippocampal complex-spike cell activity in rats performing a nonspatial radial maze task. J Neurosci 14:6553-6563. 